Article

\title{
Enhancement of Skin Anti-Inflammatory Activities of Eclipta prostrata L. from the Ultrasonic Extraction Process
}

\author{
Hyeon Yong Lee \\ Department of Food Science and Engineering, Seowon University, Cheongju 361-742, Korea; \\ hyeonl@seowon.ac.kr; Tel.: +82-43-299-8471; Fax: +82-43-299-8470 \\ Received: 17 November 2017; Accepted: 21 November 2017; Published: 28 November 2017
}

\begin{abstract}
This work first showed that the skin anti-inflammatory activities of Eclipta prostrata L. (E. prostrata L.)n be increased through an ultrasonic extraction process at a frequency of $120 \mathrm{kHz}$ with $70 \%$ ethanol at $40{ }^{\circ} \mathrm{C}$ for $6 \mathrm{~h}$. The extract from the ultrasound extraction (UE) contained $378.6 \mathrm{mg} / 100 \mathrm{~g}$ of wedelolactone (a major bioactive substance in E. prostrata L.), compared with the $172.9 \mathrm{mg} / 100 \mathrm{~g}$ from a conventional extraction process with $70 \%$ ethanol at $80{ }^{\circ} \mathrm{C}$ for $12 \mathrm{~h}$ (EE). The UE showed less than $10 \%$ of low cytotoxicity against normal fibroblast cells, and also exhibited much higher antioxidant activities than that from the EE when treating with $0.3 \mathrm{mg} / \mathrm{mL}$ of the extracts. It was proved that the high antioxidant activities of the UE were closely correlated with the enhancement of skin anti-inflammatory activities by effectively suppressing the production of tumor necrosis factor-alpha and interleukin-6 from macrophages. The production of prostaglandin $E_{2}$ from human skin cells was also greatly reduced, compared with the EE for all ranges of the treatments. These results strongly indicate that the various biological activities of E. prostrata L. can be improved by a simple ultrasound extraction process because of the high elution of bioactive substances even at a low temperature.
\end{abstract}

Keywords: Eclipta prostrata L.; ultrasound extraction; antioxidant; skin anti-inflammatory activities

\section{Introduction}

Eclipta prostrata L. is an annual plant belonging to the Asteraceae family, and it mainly grows in wetlands in the central and southern areas of Korea [1] at a height of $30-60 \mathrm{~cm}$. E. prostrata L. is also called Pungjsang in oriental medicine, and is known to be highly effective for hemostasis, drainage, and white hair [2]. With regard to the other efficacies of E. prostrata L., research on its anti-inflammatory and antidiabetic efficacies, blood pressure-lowering effects, antimicrobial activity, anticancer activity, and antioxidant effects, among others, has been conducted [2-6].

Among these activities, the anti-inflammatory activities of E. prostrata L. have been reported, as much interest has been given to the importance of studying anti-inflammation because of severe environmental stress and unbalanced or overly nutritive foods, among others [7]. The inflammatory responses are involved in immunity. The response is initiated by the immune system and generated by a variety of stimuli occurring outside the body; it is the restoration of deformed or damaged tissues of the human body caused by relevant stimuli to their original states [8]. When stimulated externally, the macrophages present in the body secrete nitric oxide (NO), cytokines, and prostaglandinE $\mathrm{P}_{2}\left(\mathrm{PGE}_{2}\right)$ to resist the relevant stimuli. $\mathrm{PGE}_{2}$ promotes the secretion of interleukin-6 (IL-6) and tumor necrosis factor- $\alpha$ (TNF- $\alpha)$ - known as inflammatory cytokines-to initiate the immune response to infection by external stimuli [9]. Although these actions protect the human body through inflammation, the excessive NO production occurring at this time becomes a dangerous factor that may cause mutation in the human body and induce toxicity [10]. Active oxygen has been known to be a main 
cause of the occurrence of excessive inflammation, and it has been found to cause inflammation through mediators such as proteins and lipids in the body [11].

An ultrasonic extraction process can be used to process plant resources because it can facilitate extraction and maximize the elution volume of the relevant active substance because of the high vibration energy generated during ultrasonic treatment [12]. The ultrasonication extraction process has been proven to efficiently destroy the hard cell walls of natural resources with high efficiency $[13,14]$. Moreover, ultrasound extraction could be an excellent alternative for avoiding high temperature during the processes, especially for extracting heat labile substances from natural resources, and it is also considered to be an excellent green process. However, there have not been many studies employing a simple ultrasonic extraction in processing the plant resources, compared to the cases of applying more complex approaches combining conventional extraction with ultrasonic processes [14]. Therefore, in this work, a more realistic extraction process that uses ethanol-an edible extraction solvent-will be introduced at a relatively low temperature by employing a simple ultrasonic extraction process alone (not in combination with other processes), which will minimally break down the structure and efficacy of wedelolactone, a major active substance of E. prostrata that has been known to have the anti-inflammatory activities [15]. The promotion of the elution of this component will be considered to be closely associated with the enhancement of anti-inflammatory efficacy. Then, the results of this work could be utilized to develop a new bioresource for cosmeceutical purposes through a simple ultrasonic extraction process.

\section{Materials and Methods}

\subsection{Materials and Preparation of the Samples}

The cells used in the experiments, CCD-986sk and RAW 264.7, were purchased from the Korean Cell Line Bank (KCLB, Seoul, Korea). These cells were cultured in a Dulbecco's Modified Eagle Medium (DMEM) medium with added $10 \%$ fetal bovine serum (Gibco, Carlsbad, CA, USA) at $37^{\circ} \mathrm{C}$ and $5 \% \mathrm{CO}_{2}$. All the other reagents used were purchased from Sigma-Aldrich (St. Louis, Mo., USA). For the conventional ethanol extraction (EE), $100 \mathrm{~g}$ of dried E. prostrata L. (harvested in 2015, Heongsung, Korea) were extracted with $1 \mathrm{~L}$ of $70 \%$ ethanol at $8{ }^{\circ} \mathrm{C}$ for $12 \mathrm{~h}$ with a vertical reflux condenser. For the ultrasonic extraction (UE), $100 \mathrm{~g}$ of dried E. prostrata $\mathrm{L}$. with $1 \mathrm{~L}$ of $70 \%$ ethanol was put into an ultrasonic extractor with a temperature controller by circulating cold or warm water as setting the temperature (AUG-R3-900, Asia Ultrasonic, Bucheon, Korea) and extracted at a frequency of $120 \mathrm{kHz}$ with the input power of $300 \mathrm{~W} / \mathrm{cm}^{2}$ for $6 \mathrm{~h}$ at $40{ }^{\circ} \mathrm{C}$. Thereafter, each of the two extracts was filtered through a vacuum filter, concentrated by a rotary evaporator (EYELA N-1000, Tokyo Rikakikai Co., Tokyo, Japan), and lyophilized for $72 \mathrm{~h}$ in a lyophilizer (PVTFA 10AT, Ilshin BioBase, Dongducheon, Korea) before use in the experiments.

\subsection{Measurement of Cell Cytotoxicity and Antioxidant Activities}

The cell cytotoxicity of the extract against human skin fibroblasts (CCD-986sk) was evaluated by the 3-(4,5-dimethylthiazol-2-yl)-2,5-diphenyltetrazolium bromide (MTT) method [16]: First, $6.0 \times 10^{5}$ cells $/ \mathrm{mL}$ of human skin fibroblasts was inoculated into a 96-well plate and cultured for one day at $37{ }^{\circ} \mathrm{C}$ in a $5 \% \mathrm{CO}_{2}$ incubator. Thereafter, the cultured cells were treated with various concentrations of the extracts and cultured again for one day under the same conditions described above. The supernatant of the treated sample was removed, and $1.0 \mathrm{mg} / \mathrm{mL}$ of MTT solution was added and cultured for $4 \mathrm{~h}$ at $37^{\circ} \mathrm{C}$ while minimizing exposure to light. Then, the MTT solution was removed and $200 \mu \mathrm{L}$ of Dimethyl Sulfoxide (DMSO) were added; the solution was left unattended for $30 \mathrm{~min}$ while light was blocked. The optical density was measured at a wavelength of $570 \mathrm{~nm}$.

To observe the antioxidant activities of E. prostrata L. extracts, the $\alpha, \alpha$-diphenyl- $\beta$-picrylhydrazyl $(\mathrm{DPPH})$ free radical scavenging activity was measured by the Dietz method [17]: after mixing $150 \mu \mathrm{L}$ of $0.1 \mathrm{mM}$ DPPH solution prepared with methanol as the solvent and $150 \mu \mathrm{L}$ of the extract, the mixture 
was wrapped in foil and left unattended for $30 \mathrm{~min}$ at room temperature while light was blocked. Thereafter, the optical density was checked at a wavelength of $517 \mathrm{~nm}$ by a microplate reader (Thermo Fisher Scientific, Waltham, MA, USA). The relevant values were estimated as DPPH radical scavenging activity (\%).

\subsection{Determination of Wedelolactone Contents in the Extracts}

To measure the contents of wedelolactone in the extracts from two different extraction processes, high performance liquid chromatography (HPLC, 1260 series, Agilent, Santa Clara, CA, USA) was used with a $\mathrm{C}_{18}$ column $(250 \mathrm{~mm} \times 4.6 \mathrm{~mm}$, Jupiter $5 \mathrm{u} 3000 \mathrm{~A}$, Santa Clara, CA, USA) under the following isocratic conditions [18,19]: The mobile phase was water:acetic acid:methanol (4.5:0.5:95) at a flow rate of $0.8 \mathrm{~mL} / \mathrm{min}$ measured at a wavelength of $352 \mathrm{~nm}$ with the injection of $10 \mu \mathrm{L}$ of $1000 \mathrm{ppm}$ of wedelolactone as the standard (Sigma-Aldrich, St. Louis, MO, USA).

\subsection{Estimation of the Production of Interleukin-6(IL-6), Tumor Necrosis Factor- $\alpha$ (TNF-a), and Prostaglandin $E_{2}\left(P G E_{2}\right)$}

The amounts of two different cytokines, IL- 6 and TNF- $\alpha$, produced from a mouse macrophage (RAW 264.7m KCLB, Seoul, Korea) were measured with Quantikine ELISA Mouse IL-6 and TNF- $\alpha$ kits (R\&D Systems, Minneapolis, MN, USA) as follows [20]: $5.0 \times 10^{5}$ cell/mL of RAW 264.7 cells were inoculated into a 96-well plate and cultured for one day at $37{ }^{\circ} \mathrm{C}$ with $5 \% \mathrm{CO}_{2}$. Then, various concentrations of the extracts, $1 \mu \mathrm{M}$ of vitamin $\mathrm{D}_{3}$ (cholecalciferol) dissolved in $0.1 \%$ ethanol and $1.5 \mu \mathrm{g} / \mathrm{mL}$ of wedelolactone as positive controls, respectively, were added with $25 \mu \mathrm{g} / \mathrm{mL}$ of lipopolysaccharide for one more day. Thereafter, according to the manuals of the ELISA kits, $50 \mu \mathrm{L}$ of the assay diluent was put into the 96-well plate, which was appropriately shaken. The standard prepared in the kit and the sample that had been cultured thus far were then put into the 96-well plate, which was shaken for one week and left unattended for $2 \mathrm{~h}$ at room temperature while light was blocked. Thereafter, the plate was washed with a wash buffer, and $100 \mu \mathrm{L}$ of the substrate solution was added into the plate for $30 \mathrm{~min}$ at room temperature while light was blocked. After blocking the reaction by a stop solution, the concentrations in the plate were measured at a wavelength of $450 \mathrm{~nm}$ by an ELISA reader (Thermo Fisher Scientific, Waltham, MA, USA).

The inhibition of the production of $\mathrm{PGE}_{2}$ from human skin fibroblasts (CCD-986sk, KCLB, Seoul, Korea) was measured by treating the extracts as follows [21]: $4.0 \times 10^{5}$ cell $/ \mathrm{mL}$ of human skin fibroblasts was inoculated into a 96-well plate for one day at $37^{\circ} \mathrm{C}$, treated with $150 \mu \mathrm{L}$ of each extract at various concentrations, $1 \mu \mathrm{M}$ of vitamin $\mathrm{D}_{3}$ (cholecalciferol) dissolved in $0.1 \%$ ethanol and $1.5 \mu \mathrm{g} / \mathrm{mL}$ of wedelolactone as positive controls, respectively, and again cultured for one more day. Thereafter, $50 \mu \mathrm{L}$ of the primary antibody solution was added into the plate, which was shaken at $100 \mathrm{rpm}$ and left unattended for $1 \mathrm{~h}$ at room temperature. Then, the $\mathrm{PGE}_{2}$ conjugate was added into the plate and left for $2 \mathrm{~h}$ at room temperature. The plate was washed four times using a wash buffer, and $200 \mu \mathrm{L}$ each of the substrate solutions was added to the plate for $30 \mathrm{~min}$ in a dark room. Thereafter, $100 \mu \mathrm{L}$ of a stop solution was added into the plate, and the amounts of $\mathrm{PGE}_{2}$ were measured at a wavelength of $450 \mathrm{~nm}$ by comparing with the standard curve.

\subsection{Statistical Analysis}

All of the experimental data were repeated three times, and statistical significance was analyzed by one-way Analysis of Variance (ANOVA) and Student's $t$ test (SAS, Cary, NC, USA). The least difference of the significance levels was set to $p<0.05$. 


\section{Results}

\subsection{Cell Cytotoxicity of the E. prostrata L. Extracts}

The results of estimating the cytotoxicity of the extracts from two different extraction processes were shown in Figure 1 before conducting skin anti-inflammatory activities, as safety should be the first consideration in developing bioactive substances from natural resources. Generally, low cell toxicity was observed to be approximately $8.76 \%$ of cytotoxicity against human skin fibroblasts in the addition of a maximum concentration of $0.3 \mathrm{mg} / \mathrm{mL}$ of the extract from the UE process and approximately $6.34 \%$ in the addition of the same concentration of the extract from the 70\% EE process. Compared with the results of the maximum $16 \%$ of cytotoxicity of other natural plants in treating the same concentrations in skin fibroblast cells [22], the extracts from both processes were considered safe for the cell experiments on anti-inflammatory activity.

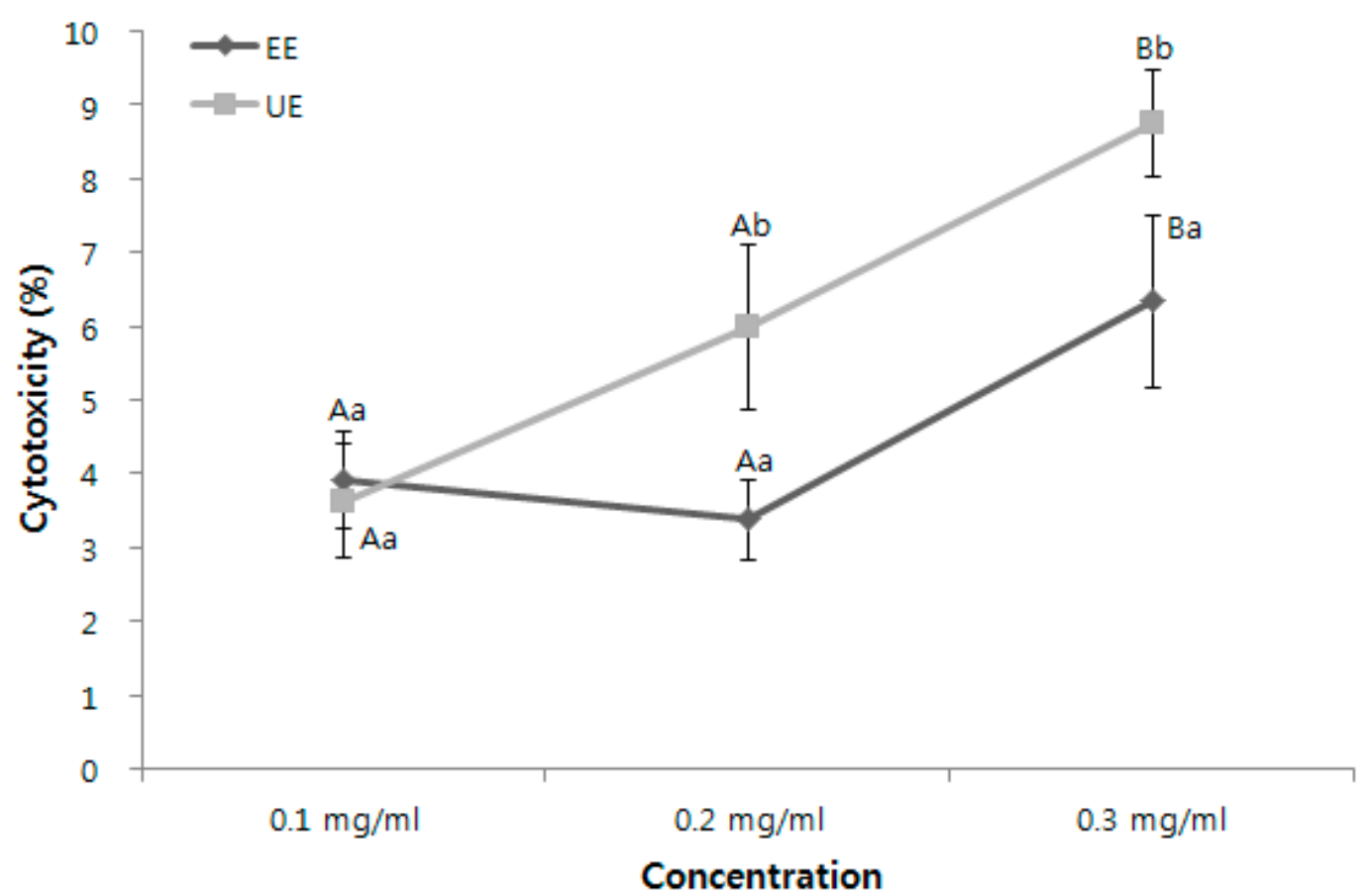

Figure 1. Cytotoxicity of the E. prostrata L. extracts against human skin fibroblasts (CCD-986sk). Mean values \pm Standard Deviation (SD) from triplicate separated experiments are shown. Means with different letters (A-B) within the same sample are significantly different at $p<0.05$ and means with different letters $(\mathrm{a}-\mathrm{b})$ within the same concentration are significantly different at $p<0.05$. (1) EE: $70 \%$ ethanol extraction at $80^{\circ} \mathrm{C}$, (2) UE: ultrasonic extraction with $70 \%$ ethanol at $40{ }^{\circ} \mathrm{C}$.

\subsection{Wedelolactone Contents and Antioxidant Activities of the Extracts}

As shown in Figure 2, the wedelolactone amount of $378.6 \mathrm{mg} / 100 \mathrm{~g}$ in the UE was higher than that of $179.2 \mathrm{mg} / 100 \mathrm{~g}$ in the EE from the conventional extraction process. This amount was two times higher than that in ultrasonic process, as well as that in the other reported results in the range of $100-400 \mathrm{mg} / 100 \mathrm{~g}[23,24]$. This result indicates that the UE may play an important role in improving the extraction yield of wedelolactone because of the minimal destruction of heat-labile wedelolactone caused by the low temperature extraction process, even at low temperature [25]. Therefore, the extract from the ultrasonic process is expected to have good antioxidant activities because wedelolactone is a family of coumarin known to have high antioxidant activity and anti-inflammatory efficacy $[15,26]$. 

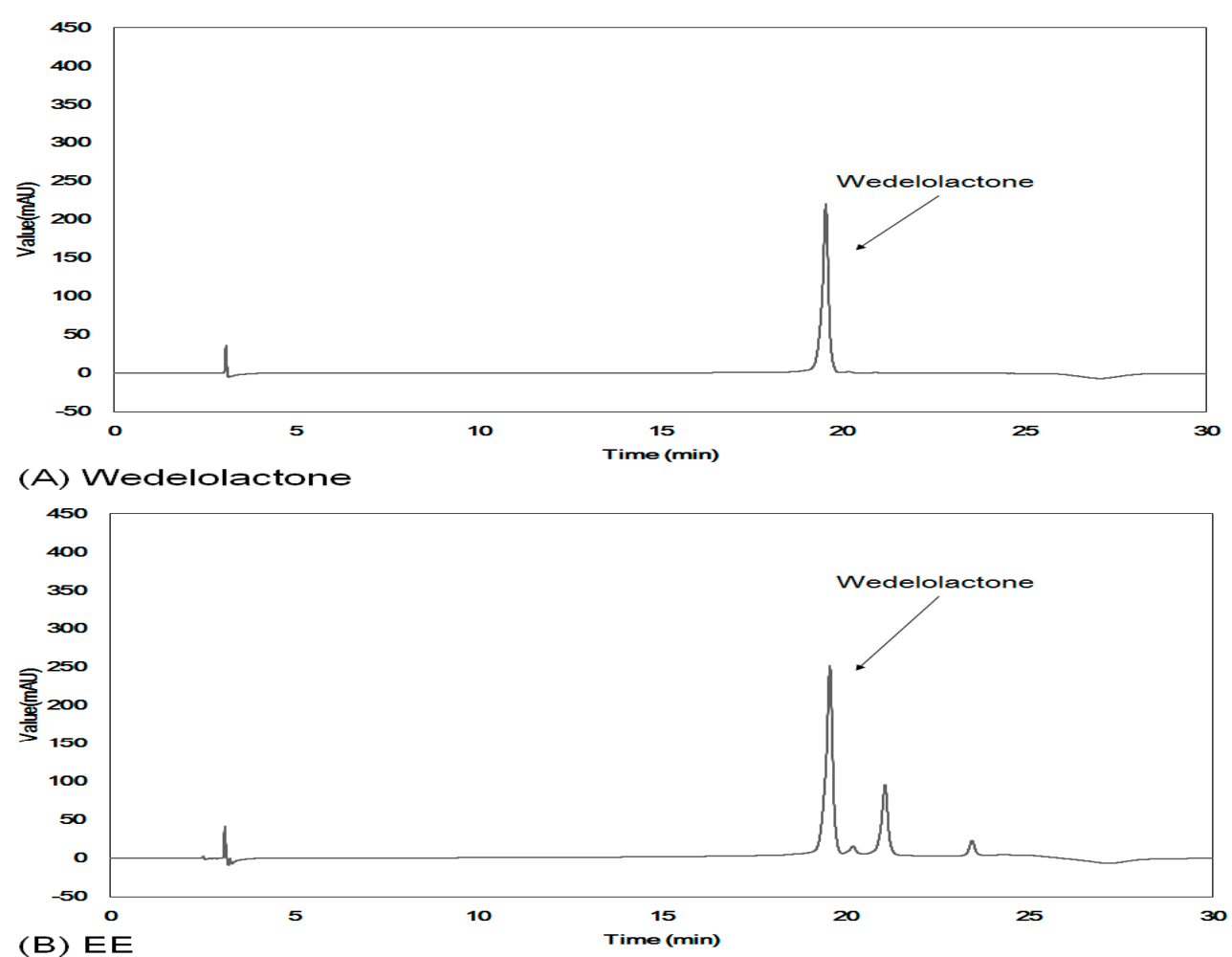

(B) $E E$

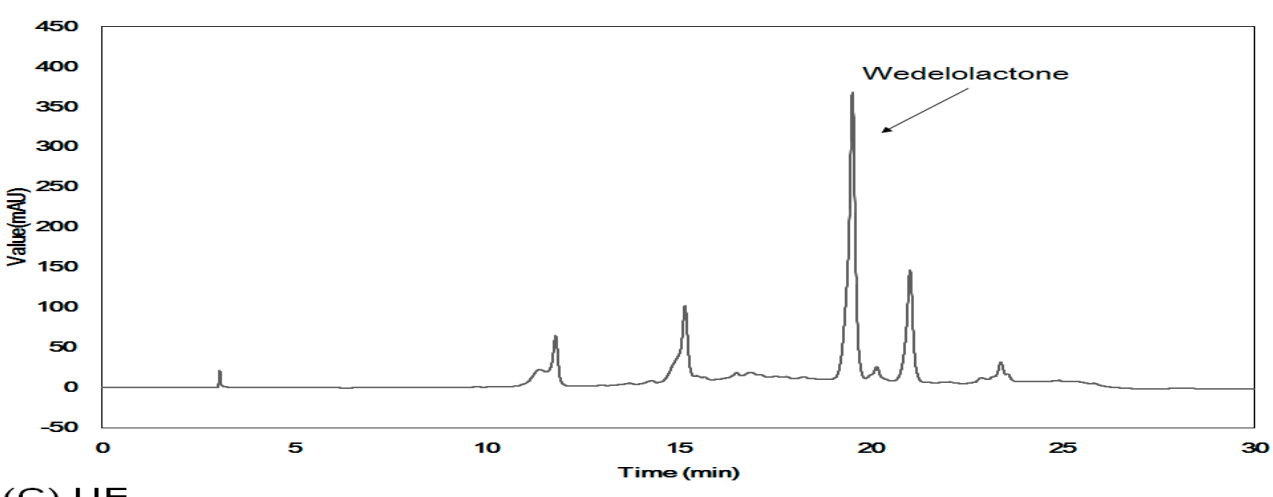

(C) UE

Figure 2. Comparison of High Performance Liquid Chromatography (HPLC) chromatograms of E. prostrata L. extracts from two different extraction processes. (A): Wedelolactone, a standard, (B) EE: $70 \%$ ethanol extraction at $80^{\circ} \mathrm{C},(\mathrm{C})$ UE: ultrasonic extraction with $70 \%$ ethanol at $40{ }^{\circ} \mathrm{C}$.

Figure 3 compares the antioxidant activities of the extracts from two processes: The EE showed a scavenging activity level of $65.21 \%$ at a maximum concentration of $0.3 \mathrm{mg} / \mathrm{mL}$ while the UE exhibited an activity level of $70.35 \%$. This result strongly implies that the DPPH free radical scavenging activity of the E. prostrata L. extract was increased through the ultrasonic extraction process. Moreover, the scavenging activity of the UE was a little lower than or even similar to that of ascorbic acid, a positive control in measuring antioxidant activities. Compared with $62.98 \%$ of the DPPH radical scavenging activity in the addition of $1.0 \mathrm{mg} / \mathrm{mL}$ of Agastache rugosa O. Kuntze extract that has similar biological activities, even though this plant did not contain the same bioactive substance, wedelolactone [27], the UE of the E. prostrata L. extract showed a higher scavenging activity of $70.35 \%$ at a concentration of $0.3 \mathrm{mg} / \mathrm{mL}$. 


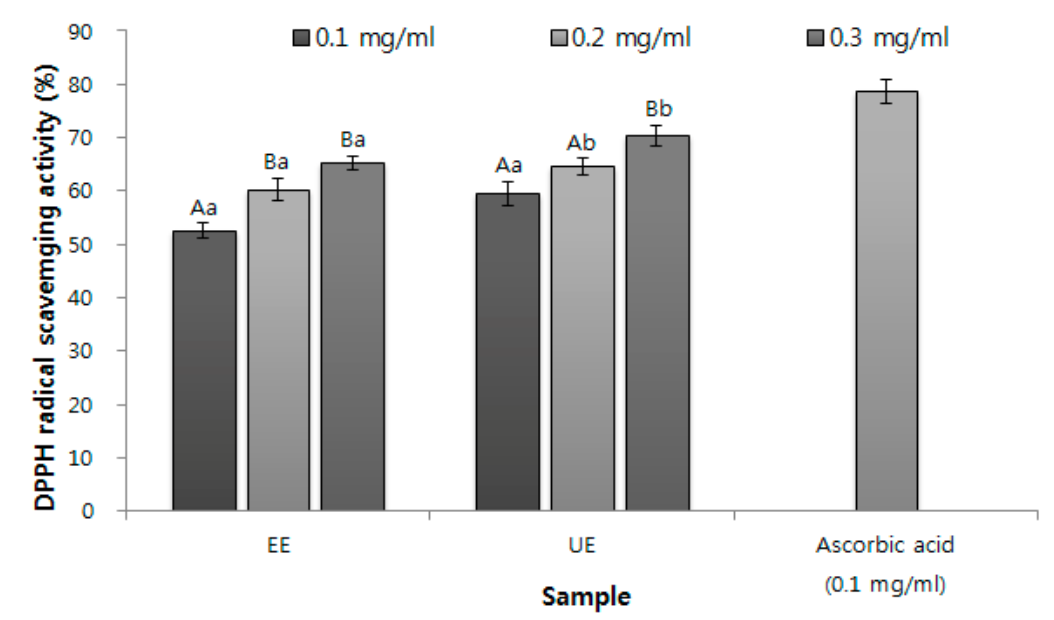

Figure 3. DPPH ( $\alpha, \alpha$-diphenyl- $\beta$-picrylhydrazyl) radical scavenging activities of E. prostrata L. extracts according to two different extraction processes. Mean values \pm SD from triplicate separated experiments are shown. Means with different letters (A-B) within the same sample are significantly different at $p<0.05$, and means with different letters $(\mathrm{a}-\mathrm{b})$ within the same concentration are significantly different at $p<0.05$. (1) EE: $70 \%$ ethanol extraction at $80^{\circ} \mathrm{C}$, (2) UE: ultrasonic extraction with $70 \%$ ethanol at $40{ }^{\circ} \mathrm{C}$.

In previous studies that identified the antioxidant effects of E. prostrata L. extract, active oxygen was indicated to induce inflammation through various media, such as internal lipids and proteins. Therefore, the antioxidant activity of the E. prostrata L. extracts is considered to be associated with anti-inflammatory efficacy [11]. Attempts have been made to prove its anti-inflammatory efficacy—specifically the effects on human skin anti-inflammation for cosmetic applications.

\subsection{Suppressing the Production of Cytokines and $P G E_{2}$ for Skin Anti-Inflammation}

In general, the excessive expression of TNF- $\alpha$ induces a decrease in blood pressure, damage to the metabolic process, and a reduction in myocardial contractility, thus leading to many adverse effects on the body; therefore, IL-6 plays a major role in the TNF- $\alpha$ receptor release [28,29]. As shown in Figure 4A, the decrease in IL-6 production from macrophages was observed in the addition of both the UE and EE. However, only $43.3 \mathrm{pg} / \mathrm{mL}$ of IL- 6 was produced in the addition of the UE compared with the $101.6 \mathrm{pg} / \mathrm{mL}$ measured in the EE. This finding clearly indicates that the E. prostrata L. extract from the ultrasound process improved its anti-inflammatory efficacy. Besides the comparison with two different extracts, in Figure $4 \mathrm{~A}-\mathrm{C}$, the effects of vitamin $\mathrm{D}_{3}$ (cholecalciferol) on the production of cytokines and $\mathrm{PGE}_{2}$ were also examined as a positive control, since vitamin $\mathrm{D}_{3}$ (mainly existing in humans), has been known to have strong anti-inflammatory activities and even on the skin [30-32]. Overall, the efficacy of vitamin D3 in inhibiting the production of IL-6, TNF-alpha, and PGE 2 seemed to be much better than those of the EE with the addition of the highest concentration of $0.3(\mathrm{mg} / \mathrm{mL})$, while it was somewhat higher or similar to those of the UE treatment at the same concentrations, which implies that the UE must have skin anti-inflammatory effects and is better than the EE. The results also indicate that its efficacy could be close to that of vitamin $\mathrm{D}$ in properly treating the concentrated extracts into the cells.

In addition to considering the effects of vitamin $\mathrm{D}$ as a positive control, the anti-inflammatory activities of wedelolactone should also be compared with those of two extracts, since there were several other components observed in the UE, as shown in Figure 2. To do so, $1.5 \mu \mathrm{g} / \mathrm{mL}$ of wedelolactone as another positive control—corresponding to the same amounts of wedelolactone existed in $0.3 \mathrm{mg} / \mathrm{mL}$ of the extracts-were treated as shown in Figure $4 \mathrm{~A}-\mathrm{C}$, since ca. $400 \mathrm{mg} / 100 \mathrm{~g}$ of wedelolactone (actually $378.6 \mathrm{mg} / 100 \mathrm{~g}$ ) in the UE were estimated by HPLC analysis as shown in Figure 2. However, in general, the effects of wedelolactone on the inhibition of producing two cytokines and $\mathrm{PGE}_{2}$ were 
definitely lower than those of the UE, but better than those of the EE at the highest treatment. This result clearly indicates that better skin anti-inflammation activities of the UE must be caused by synergistic effects of higher amounts of other components in the UE that did not exist in the EE along with the efficacy of wedelolactone. It can also imply that the crude extracts are often useful in enhancing biological activities rather than purifying a pure single component from the medicinal plants from the standpoint of economic feasibility.
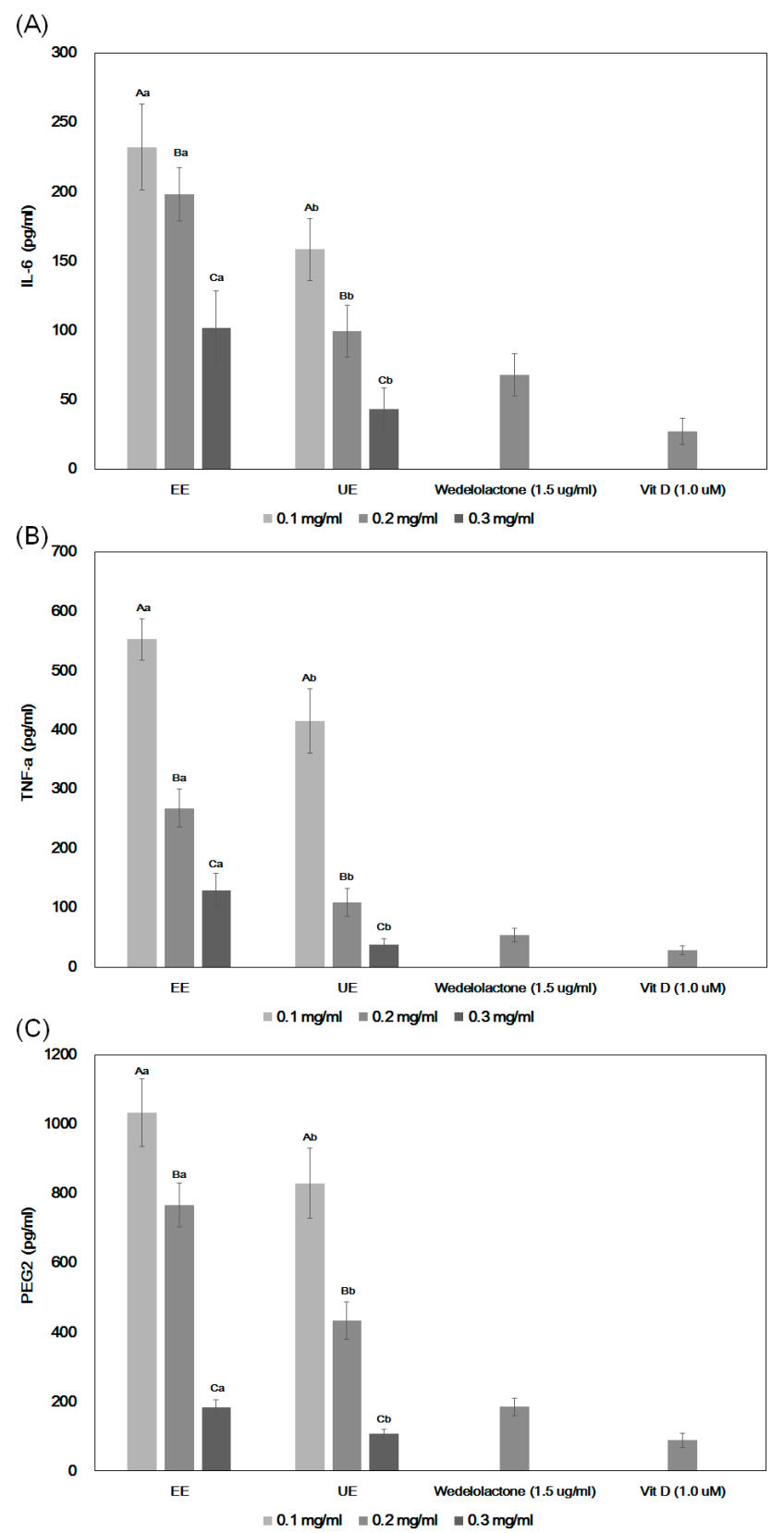

Figure 4. Comparison of (A) interleukin-6 (IL-6), (B) tumor necrosis factor- $\alpha$ (TNF- $\alpha$ ), and (C) prostaglandin $\mathrm{E}_{2}\left(\mathrm{PGE}_{2}\right)$ production in treating three different concentrations of the E. prostrata L. extracts along with $1.0 \mu \mathrm{M}$ of vitamin $\mathrm{D}_{3}$ and $1.5 \mu \mathrm{g} / \mathrm{mL}$ of wedelolactone as positive controls. Mean values $\pm \mathrm{SD}$ from triplicate separated experiments are shown. Means with different letters (A-B) within the same sample are significantly different at $p<0.05$, and means with different letters $(\mathrm{a}-\mathrm{b})$ within the same concentration are significantly different at $p<0.05$. (1) EE: $70 \%$ ethanol extraction at $80^{\circ} \mathrm{C}$, (2) UE: ultrasonic extraction with $70 \%$ ethanol at $40^{\circ} \mathrm{C}$. 
Similarly, in Figure 4B, both extracts showed concentration-dependent decreases in TNF- $\alpha$ production. Moreover, $37.2 \mathrm{pg} / \mathrm{mL}$ vs. $129.5 \mathrm{pg} / \mathrm{mL}$ of TNF- $\alpha$ production was estimated in the addition of the maximum concentration of $0.3 \mathrm{mg} / \mathrm{mL}$ of the UE and $\mathrm{EE}$, respectively. In general, the effects of vitamin $\mathrm{D}_{3}$ were better or similar to that of the UE, but much better than the EE, while the effects of wedelolactone were lower than that of the UE, but higher than the EE. These results can be compared with the experimental data on Aronia, which is also known to have similar biological activities [21], where $100 \mathrm{pg} / \mathrm{mL}$ of IL- 6 and $120 \mathrm{pg} / \mathrm{mL}$ of TNF- $\alpha$ were produced in treating the same concentrations. Therefore, the UE can be considered to have good or even better anti-inflammatory activities than other natural resources.

To confirm whether the high anti-inflammatory activities of the E. prostrata L. extract could be attributed to skin anti-inflammatory effects, the inhibition of $\mathrm{PGE}_{2}$ production from human skin fibroblasts was also observed, as $\mathrm{PGE}_{2}$ plays a role in promoting the generation of inflammatory cytokine IL- 6 and TNF- $\alpha$ and in affecting the skin $[9,29,33]$. As shown in Figure 4 C, the EE generated approximately $183.3 \mathrm{pg} / \mathrm{mL}$ of $\mathrm{PGE}_{2}$ at a maximum concentration of $0.3 \mathrm{mg} / \mathrm{mL}$, whereas the UE produced only $107.7 \mathrm{pg} / \mathrm{mL}$, which is approximately $40 \%$ lower than the value from the EE. The efficacy of $\mathrm{PGE}_{2}$ seems to be similar to the anti-inflammatory effects of inhibiting the cytokine productions (as shown in Figure 4A,B), and the effects of vitamin $\mathrm{D}_{3}$ and wedelolactone also showed similar patterns. Study of the anti-inflammatory efficacy of Aronia extract at a concentration of $1.0 \mathrm{mg} / \mathrm{mL}$ showed a $\mathrm{PGE}_{2}$ yield corresponding to that of E. prostrata L. at $0.3 \mathrm{mg} / \mathrm{mL}$ [21].

According to the above results, the extract from the UE process had a higher anti-inflammatory activity than that from the $70 \%$ EE process, which is a conventional extraction process. This result could be attributed to the synergistic effects of wedelolactone and other components, which were increased through ultrasonication, and affected the anti-inflammatory activity so that the anti-inflammatory of E. prostrata L. increased. In addition, as previous studies identified that wedelolactone-a component of E. prostrata L.-is rapidly destroyed at temperatures higher than $60{ }^{\circ} \mathrm{C}$, the low-temperature ultrasonic extraction process presented in this study could be an alternative process that minimizes the destruction of wedelolactone and enhances the extraction efficiency [25].

\section{Discussion}

Several reports have been conducted on the anti-inflammatory activities of the E. prostrata L. extract and wedelolactone (a family of coumarin), which is one of the major biologically active substances. Conversely, in this work, the skin anti-inflammatory activities of the E. prostrata L. extract were reported for the first time by comparing with the effects of wedelolactone and vitamin $\mathrm{D}$ as positive controls. The simple ultrasonic process at a relatively low temperature has been proved to be effective in extracting heat-labile natural bioresources by showing that the UE processed at $40{ }^{\circ} \mathrm{C}$ improved the extraction yield of wedelolactone from E. prostrata L. up to $60 \%$ more than that from conventional extraction with $70 \%$ ethanol at $80^{\circ} \mathrm{C}$. Similar results on the processing of many medicinal herbs were also reported elsewhere. However, interestingly enough, the extract from the UE process exhibited better efficacy for all the various skin anti-inflammatory experiments than those from other extraction processes, possibly because of the high elution of the intact form of wedelolactone and also other components under a low-temperature extraction condition. This result implies that high amounts of a strong antioxidant compound (wedelolactone) and other bioactive substances in the UE can synergistically enhance its antioxidant activities, and which eventually result in better skin anti-inflammatory activities than others-even better than the case of adding the same amount of wedelolactone existing in the extract. These activities were also found to be a little lower or even close to that of vitamin $\mathrm{D}_{3}$ as a positive control. Although a more detailed relationship between antioxidant activities and skin anti-inflammatory activities of the extract should be determined further as well as identifying other bioactive substances in the extract, these results indicate the possibility that E. prostrata L. and wedelolactone can be used for cosmeceutical applications. 


\section{Conclusions}

This work clearly demonstrated that the ultrasonic extraction process can help to improve the extraction yield of biologically active substances from natural resources at relatively low temperature, which should be important in processing heat labile components. It was also proved that the increase of the extraction yield of an intact form of the target components in the plant could play an important role in enhancing its biological activities, especially the enhancement of the skin anti-inflammatory activities of E. prostrata L. by high elution of wedelolactone and also synergistic effects of other biologically active components in the extract. This work also provided the evidence that there must be a strong correlation between antioxidant activities and skin anti-inflammation activities. Therefore, we could conclude that the E. prostrata L. extract from a simple ultrasonic process at low temperature could be used as a new cosmeceutical resource with its good skin anti-inflammatory activities. From an economic standpoint, these results could recommend the use of the crude extracts to expect better biological activities in functional food and cosmeceutical applications, not a purified single component from medicinal herbs.

Conflicts of Interest: The author declares no conflict of interest.

\section{References}

1. Chang, C.A. A study on the color resolution of hair by using the extract of hanryencho. J. Investig. Cosmetol. 2006, 2, 97-109.

2. Moon, Y.H.; Woo, E.R.; Lee, D.H. Hypoglycemic effect of polysaccharide isolated from Eclipta alba L. Korean J. Pharm. 2003, 34, 246-249.

3. Yun, J.S.; Chung, B.H.; Kim, N.Y.; Seong, N.S.; Lee, H.Y.; Lee, J.H.; Kim, J.D. Screening of 94 plant species showing ACE inhibitory activity. Korean J. Med. Crop Sci. 2003, 11, 246-251.

4. Chon, S.U.; Kim, D.I.; Choi, Y.S. Assessment on insecticidal and fungicidal activities by aerial part extracts from several compositae plants. Korean J. Weed Sci. 2003, 23, 81-91.

5. Jung, Y.D.; Lee, H.; Lee, B.R.; Yim, Y.K. The effect of anti-cancer and immune response improvement of ELP (Eclipta prostrata) herbal-acupuncture into chok-samni (St36). J. Korean Acupunct. Moxib. Soc. 2003, 20, 141-153.

6. Majumdar, A.S.; Saraf, M.N.; Kamble, R.Y. Antioxidant activity of Eclipta alba L. in normal rat liver. Iran. J. Pharmacol. Ther. 2010, 9, 103-105.

7. Arunachalam, G.; Subramanian, N.; Pazhani, G.P.; Ravichandran, V. Anti-inflammatory activity of methanolic extract of Eclipta prostrata L. (Astearaceae). Afr. J. Pharm. Pharmacol. 2009, 3, 97-100.

8. Zamora, R.; Vodovotz, Y.; Billiar, T.R. Inducible nitric oxide synthase and inflammatory diseases. Mol. Med. 2000, 6, 347-373. [PubMed]

9. Medaniel, M.L.; Kwon, G.; Hill, J.R.; Marshall, C.A.; Corbett, J.A. Cytokines and nitric oxide inislet inflammation and diabetes. Proc. Soc. Exp. Biol. Med. 1996, 211, 24-32. [CrossRef]

10. Choi, I.Y.; Song, Y.J.; Lee, W.H. DPPH radical scavenging effect and antimicrobial activities of some herbal extracts. Korean J. Horticul. Sci. Technol. 2010, 28, 871-876.

11. Takizawa, S. Free radical production in ischemic cerebrovascular disease. Nihon Ronen Igakkai Zasshi 2003, 40, 319-321. [CrossRef] [PubMed]

12. Park, K.A.; Hong, I.K.; Kim, W.I.; Jeong, K.W. Ultrasonic energy effects on squalene extraction from amaranth seed. Appl. Chem. 2000, 4, 149-152.

13. Yamada, T.; Sakaguchi, K. Comparative studies on Chlorella cell walls: Induction of protoplast formation. Arch. Microbiol. 1982, 132, 10-13. [CrossRef]

14. Zheng, H.; Yin, J.; Gao, Z.; Huang, H.; Ji, X.; Dou, C. Disruption of Chlorella vulgaris cells for the release of biodiesel-producing lipids: A comparison of grinding, ultrasonication, bead milling, enzymatic lysis, and microwaves. Appl. Biochem. Biotechnol. 2011, 164, 1215-1224. [CrossRef] [PubMed]

15. Deng, H.; Fang, Y. Anti-inflammatory gallic acid and wedelolactone are G protein-coupled receptor-35 agonists. Pharmacology 2012, 89, 211-219. [CrossRef] [PubMed] 
16. Mosmann, T. Rapid colorimetric assay for cellular growth and survival: Application to proliferation and cytotoxicity assays. J. Immunol. Methods 1983, 65, 55-63. [CrossRef]

17. Dietz, B.M.; Kang, Y.H.; Liu, G.; Eggler, A.L.; Yao, P.; Chadwick, L.R.; Pauli, G.F.; Farnsworth, N.R.; Mesecar, A.D.; van Breeman, R.B.; et al. Xanthohumol isolated from Humulus lupulus inhibits menadione-induced DNA damage through induction of Quinone reductase. Chem. Res. Toxicol. 2005, 18, 1296-1305. [CrossRef] [PubMed]

18. Patel, M.; Verma, R.; Srivastav, P. Antioxidant activity of Eclipta alba extract. J. Med. Plants Stud. 2016, 4, 92-98.

19. Kumar, S.; Dhanani, T. Development and validation of a rapid high performance liquid chromatography-Photodiode array detection method for estimation of a bioactive compound wedelolactone in extracts of Eclipta alba. Braz. J. Pharm. Sci. 2013, 49, 57-64. [CrossRef]

20. Kim, N.Y.; Lee, H.Y. Skin anti-inflammatory activity of nano-encapsulated Aronia melanocarapa extracts. Res. J. Biotechnol. 2015, 10, 62-74.

21. Kim, N.Y.; Lee, Y.D.; Cho, S.C.; Shin, Y.C.; Lee, H.Y. Enhancement of anti-inflammation effect by fermentation process in Aronia melanocarpa (Mixchx.) Elliot extract. Korean J. Med. Crop Sci. 2014, 22, 475-482. [CrossRef]

22. Seo, Y.C.; Kim, J.S.; Kim, Y.O.; Kim, J.C.; Lee, H.Y. Immune activity of Lithospermum erythrorhizon extracted by extreme low temperature extraction process. Korean J. Med. Crop Sci. 2013, 21, 105-111. [CrossRef]

23. Gawde, A.J.; Paratkar, G.T. Production and enhancement of wedelolactone in shoot cultures of Eclipta alba. J. Herbs Spices Med. Plants 2006, 18, 203-209. [CrossRef]

24. Zhao, Y.; Peng, L.; Lu, W.; Wang, Y.; Huang, X.; Gong, C.; He, L.; Hong, J.; Wu, S.; Jin, X. Effect of Eclipta prostrata on lipid metabolism in hyperlipidemic animals. Exp. Gerontol. 2015, 62, 37-44. [CrossRef] [PubMed]

25. Patil, A.A.; Sachin, B.S.; Wakte, P.S.; Shinde, D.B. Optimization of supercritical fluid extraction and HPLC identification of wedelolactone from Wedelia calendulacea by orthogonal array design. J. Adv. Res. 2014, 5, 629-635. [CrossRef] [PubMed]

26. Yuan, F.; Chen, J.; Sun, P.P.; Guan, S.; Xu, J. Wedelolactone inhibits LPS-induced pro-inflammation via NF-kappaB pathway in RAW 264.7 cells. J. Biomed. Sci. 2013, 20, 84-94. [CrossRef] [PubMed]

27. Kim, N.Y.; Park, D.S.; Lee, H.Y. Effect of anti-skin wrinkle and antioxidant of Agastache rugosa Kentz through fermentation process of the lactic acid. Korean J. Med. Crop Sci. 2015, 23, 37-42. [CrossRef]

28. Barton, B.E. IL-6: Insights into novel biological activities. Clin. Immunol. Immunopathol. 1997, 85, 16-20. [CrossRef] [PubMed]

29. Tilg, H.; Trehu, E.; Atkins, M.B. Interleukin-6 as an anti-inflammatory cytokines: Induction of circulating IL-1 receptor antagonist and soluble tumor necrosis factor receptor $\mathrm{p} 55$. Blood 1994, 83, 113-118. [PubMed]

30. Bikle, D.D. Vitamin D and the skin: Physiology and pathophysiology. Rev. Endocr. Metab. Disord. 2012, 13, 3-19. [CrossRef] [PubMed]

31. Liu, X.; Nelson, A.; Wang, X.; Farid, M.; Gunji, Y.; Ikari, J.; Iwasawa, S.; Basma, H.; Feghali-Bostwick, C.; Rennard, S. Vitamin D modulates prostaglandinE $E_{2}$ synthesis and degradation in human lung fibroblasts. Am. J. Respir. Cell Mol. Biol. 2014, 50, 40-50. [PubMed]

32. Fletcher, J.M.; Basdeso, S.A.; Allen, A.C.; Dunne, P.J. Therapeutic use of vitamin D and its analogue in autoimmunity. Recent Pat. Inflamm. Allergy Drug Discov. 2012, 6, 22-34. [CrossRef] [PubMed]

33. Jonuleit, H.; Kühn, U.; Müller, G.; Steinbrink, K.; Paragnik, L.; Schmitt, E.; Knop, J.; Enk, A.H. Pro-inflammatory cytokines and prostaglandins induce maturation of potent immunostimulatory dendritic cells under fetal calf serum-free conditions. Eur. J. Immunol. 1997, 27, 3135-3142. [CrossRef] [PubMed]

(C) 2017 by the author. Licensee MDPI, Basel, Switzerland. This article is an open access article distributed under the terms and conditions of the Creative Commons Attribution (CC BY) license (http://creativecommons.org/licenses/by/4.0/). 